\title{
FORAGING PATTERNS OF HALICTID BEES AT FLOWERS OF CONVOLVULUS ARVENSIS ${ }^{1}$
}

\author{
BY KeITH D. WADDINGTON \\ Department of Entomology, University of Kansas, \\ Lawrence, Kansas 66045
}

\section{INTRODUCTION}

An animal may acquire food in one of three general ways: 1) it may move through the environment in search of food, independently of other animals utilizing the same resource; 2 ) it may avoid other animals, resulting in an evenly spaced distribution of animals (Ricklefs, 1973; Chapter 18); or 3) it may forage with other animals in single or mixed species groups. Group foraging has recently been described for a variety of animals: ants (Bernstein, 1975), bats (Heithaus, Opler, and Baker, 1974), and birds (Cody, 1971; Ward, 1965). Since the acquisition of food is a likely determinant of an animal's ability to survive and reproduce, the strategy used is probably a result of natural selection for individuals which forage most efficiently.

Few studies have been conducted to investigate the foraging strategies of bees. This information is essential to understanding pollen flow and the general pollination biology of natural vegetation and agricultural crops. Kalmus (1953) found that visual and olfactory cues are important in the mutual attraction of honeybees at dishes of sugar syrup, resulting in non-independent foraging. Frankie, Opler, and Bawa (1974) reported that males of Centris sp. commonly forage over the forest canopy in Costa Rica in groups of up to 300 bees. Charles D. Michener (pers. comm.) has observed bees (families Colletidae and Anthophoridae) foraging on flowers of the bush Chrysothamnus $s p$. in apparent aggregations. He has observed that while one or two bees might be at a clump of bushes at any time, large numbers seemed to appear, more or less simultaneously, at the bushes, and after a time most of them left more or less suddenly. These bees seemed to be foraging in groups, not independently from one another. In this paper quadrat censusing techniques

\footnotetext{
${ }^{1}$ Contribution number 1610 from the Department of Entomology, University of Kansas, Lawrence, Kansas 66045, U.S.A.

Manuscript received by the editor February 16, 1976.
} 
are employed to determine the foraging patterns of sweat bees (Halictidae) gathering pollen and nectar from bindweed (Convolvulus arvensis) flowers.

\section{METHODS}

All observations were made at dense floral arrays of bindweed (Convolvulus arvensis) on Campus West, The University of Kansas, Lawrence. Several acres of bindweed surrounded the test areas. Observations were made of the three prime bee visitors to the bindweed flowers: Agapostemon texanus, Augochlorella striata, and Lasioglossum (Dialictus) sp., all sweat bees of the family Halictidae. The species of Lasioglossum were difficult to discriminate in the field, so it is possible that data for more than one species of Lasioglossum were pooled under the designation Lasioglossum sp. Honeybees, bumblebees, butterflies, and moths were also observed visiting bindweed flowers for food.

The following methods were used to determine the temporal patterns of the bees within the bindweed patch. Eleven test quadrats, each $1 \mathrm{~m}^{2}(1 \times 1 \mathrm{~m})$, were delimited by string in the bindweed population. The number of halictids (individual species were not distinguished) on flowers within quadrats 1-3 on June 30,1974, and quadrats 4-7 on July 2, was recorded every two minutes from about 0830 to $1030 \mathrm{~h}$. Counts of each of the three halictid species were made every 3 minutes at quadrats 8-11 on July 3, again between 0830 and $1030 \mathrm{~h}$. At the end of each day's observations the number of flowers within each quadrat was recorded.

The spatial patterns of halictid bees were tested employing the following methods. A $12 \times 6 \mathrm{~m}$ rectangular study area, near the edge of several acres of bindweed, was delimited by string. A random numbers table (Rohlf and Sokal, 1969) was used to determine the coordinates of the southwest corner of $320.25 \mathrm{~m}^{2}(0.5 \times 0.5 \mathrm{~m})$ sample quadrats within the study area. Each of the quadrats was delimited with string in late afternoon on July 4. At 0915, 0955, and $1045 \mathrm{~h}$ on July 5 the number of bees within each of the 32 quadrats was recorded.

The chi-square test of goodness of fit was employed to test the null hypothesis that the temporal and spatial data approximate Poisson distributions, the expectation if the bees are dispersed at random. The G-test was applied to $2 \times 2$ tables to test whether the presence and absence of species pairs at bind weed are dependent on each other. 


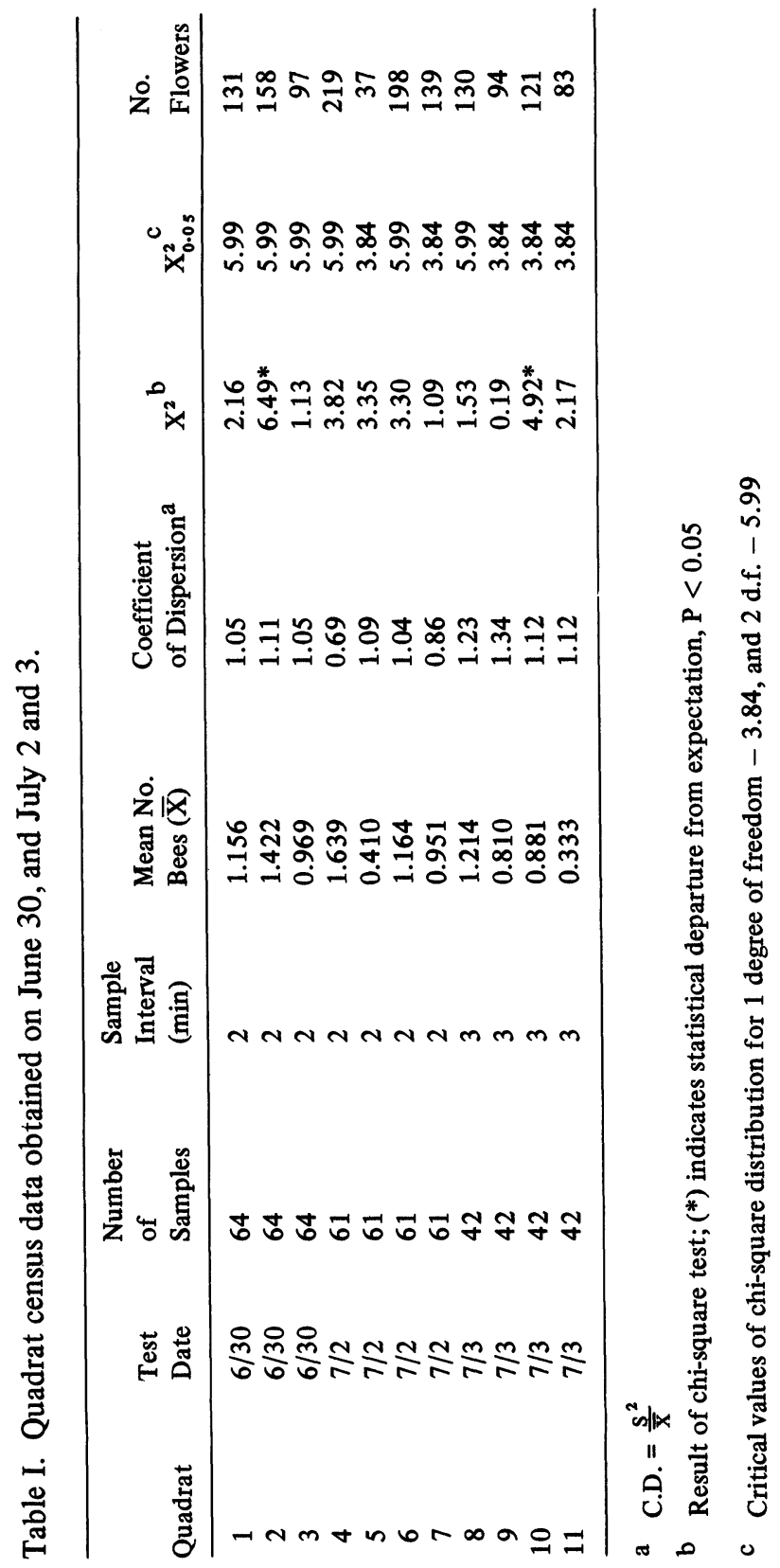




\section{RESULTS}

Bindweed plants grow along the ground, often forming dense tangled mats, and produce white or pinkish funnelform flowers. On test days anthesis began at about $0715 \mathrm{~h}$ and most flowers were fully open by $0800 \mathrm{~h}$. Nectar was produced at the base of the corolla and pollen was slowly dehisced by the 5 anthers during the morning. The flowers wilted in the early afternoon.

Halictid bees began visiting the bindweed before $0800 \mathrm{~h}$ and continued until nearly $1130 \mathrm{~h}$ when most of the nectar and pollen was depleted. During the first and last half hour of the foraging periods visits were infrequent. Censusing was conducted from about 0830 to $1030 \mathrm{~h}$ when halictid activity was generally high (Fig. 1).

The number of bees per quadrat is the Poisson variable for both the temporal and spatial quadrat sampling experiments. If the observed frequencies closely fit the expected Poisson distribution with the same mean $(\mathrm{x})$, indicating the bees are randomly dispersed over the flowers, then it can be assumed that the bees are foraging

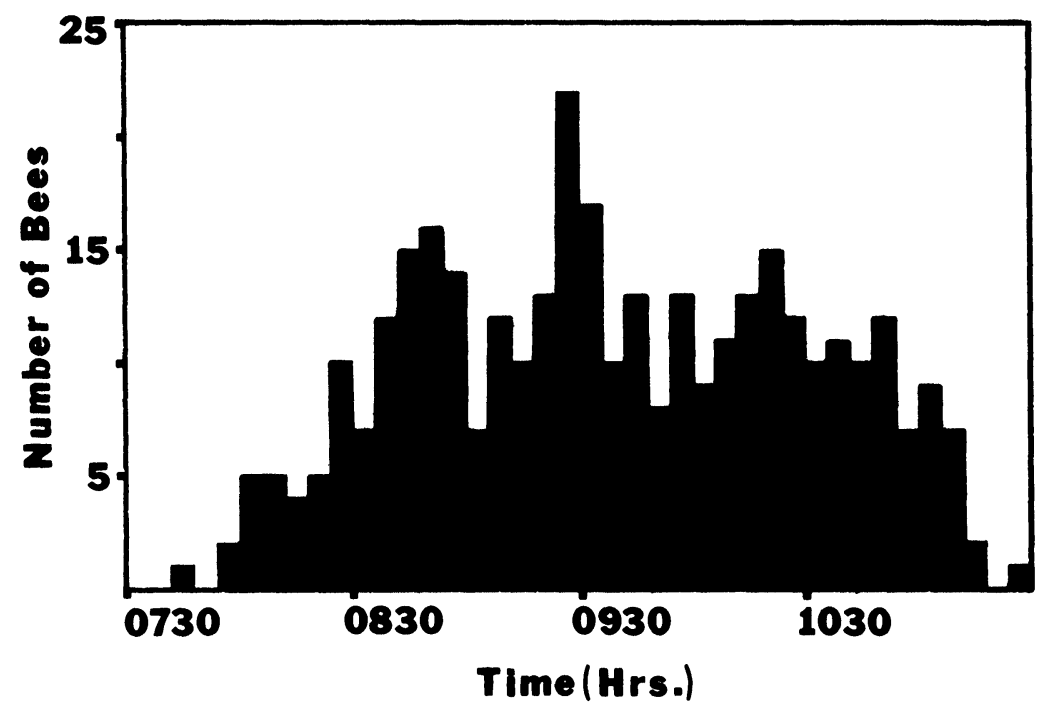

Fig. 1. Visitation frequency of Halictid bees to quadrates 4-7 (data pooled) between 0730 and $1130 \mathrm{~h}$, July 2. Each bar is the sum of bees during three consecutive censuses. 
independently of each other. In this case the coefficient of dispersion, C.D. $=\frac{S^{2}}{\bar{X}}$, (Sokal and Rohlf, 1969) will approximate $1\left(\mu=\sigma^{2}\right.$ for the Poisson distribution). If, on the other hand, the observed distribution of bees per sample departs significantly from the expected Poisson distribution and C.D. $<1$ or $>1$ then the bees can be assumed to be evenly distributed over the flowers or foraging in groups (either single or multiple species groups), respectively.

Temporal patterns - Counts taken at the eleven quadrats were tested against the expected Poisson distribution, based on the observed sample means, to determine the temporal patterns of the halictids (individual species samples taken at quadrats 8-11 are pooled for purposes of this analysis). The sample means are correlated with the number of flowers within the same quadrats (Fig. 2). In fact, flower density appears to be an excellent predictor

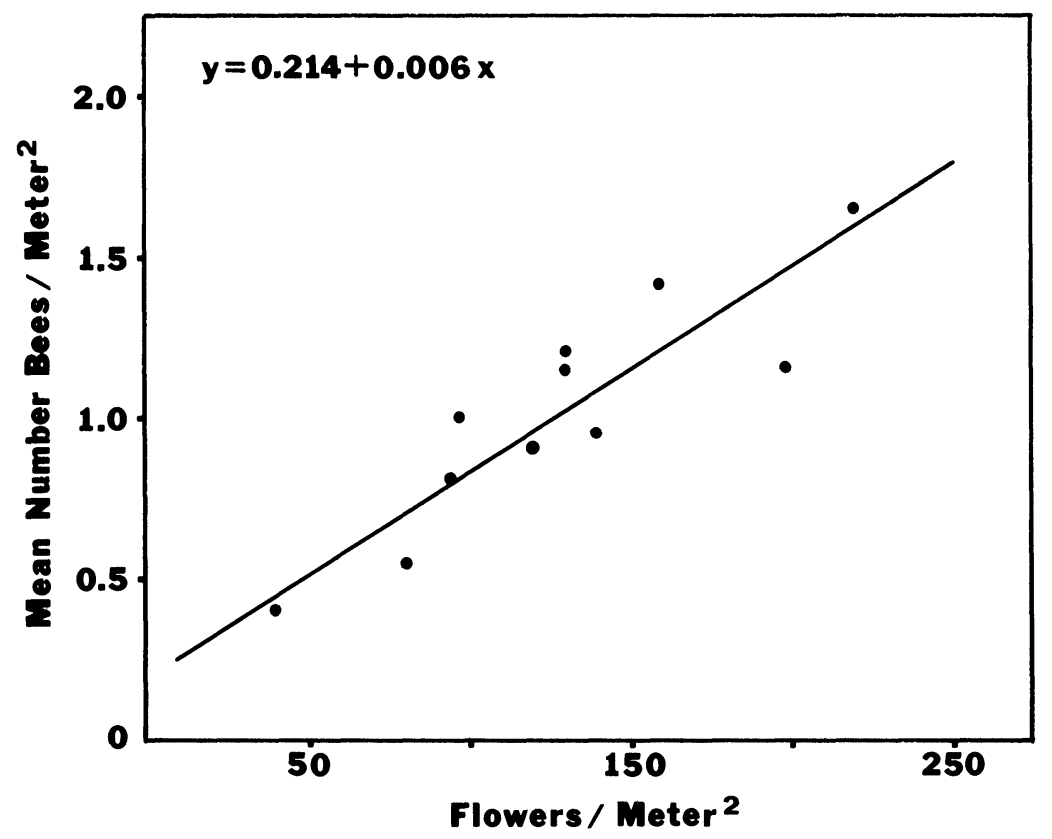

Fig. 2. Regression of mean number of bees per meter as a function of number of flowers per meter ${ }^{2}$. Dark circles represent data from 11 quadrats; data from Table $I$. 
of mean bee density $(\mathrm{Y}=0.214+0.006 \mathrm{X}$; the slope is significantly different from zero; $\mathrm{F}$ - test, $\mathrm{P}<0.001$ ).

The null hypothesis of random dispersion of the halictids was rejected (chi-square test; $P<0.05$ ) for only two of the eleven frequency distributions (Table 1). In both cases, C.D. $>1$. Also, analyses of individual species data taken on July 3 (quadrats 8-11) show no association of individuals of the three possible species pairs ( $G$ - test on $2 \times 2$ tables; $P>0.05$ for each comparison). The data indicate that the halictid species are primarily foraging at bindweed independently of one another; however, it is possible that the bees may also exhibit clumped dispersal patterns indicating a multiple halictid species group foraging strategy.

Samples of the three halictid species at quadrats 8-11 were obtained to determine the temporal patterns of individual halictid species. All twelve frequency distributions (4 distributions for each species) were not significantly different (chi-square test; $P>0.05$ ) from the expected Poisson distributions. The bees appear to forage independently of conspecifics.

Spatial patterns - The data obtained during three tests on July 5 are not significantly different from the three respective expected frequency distributions. These data indicate, again, that the bees are distributed at random and foraging independently of each other.

\section{Discussion}

The temporal and spatial data indicate that Agapostemon texanus, Augochlorella striata, and Lasioglossum (Dialictus) $s p$. forage at bindweed flowers as individuals, independently of one another. The bees appear not to forage in single or multiple species groups, nor are the patterns repulsed as might be expected for organisms utilizing the same resource in the same time and space. Bee numbers per area increased linearly with flower density (Fig. 2) indicating that even at the highest bee densities encountered in this study the threshold distances between individuals were not met (Ricklefs, 1973). If bee density were increased, the threshold of bees' individual distance would be reached, perhaps resulting in repulsed spatial and temporal patterns.

The possibility still remains that species associations occur among the bees, and that the spatial and temporal patterns are other than random. This is because the results obtained using 
quadrat sampling techniques are influenced by the size of the quadrat (Pielou, 1969). It would have been desirable in this study to use larger sample quadrats in addition to those employed. This was not done because pilot studies indicated that as quadrat size increased, it became increasingly difficult to accurately count the bees in a very short period of time.

Other studies suggest that animal foraging patterns vary according to resource distribution and abundance. Michener's observations (pers. comm.) of seemingly clumped bee patterns, were made in a semi-desert area of southern California at a very sparse resource, Chrysothamnus bushes. Two strategies are exhibited by the ant, Veromessor pergandei, depending on food abundance (Bernstein, 1975). When food is abundant the ants forage independently, but when food is scarce they forage in groups. Some birds forage in flocks when food is uniformly distributed and scarce (Cody, 1971). Heithaus et al. (1974) found that some bats lap only a small portion of the nectar during a flower visit, thereby maintaining an abundant resource. These bats forage independently.

In the present study, bees were observed foraging at very dense arrays of $C$. arvensis flowers. The abundance and uniformity of the resource were maintained by the continuous replenishment of pollen and nectar. Pollen was dehisced during much of the bees' foraging period (personal observation), and unpublished data provided by $\mathrm{R}$. W. Thorpe suggest that nectar may be continuously secreted from time of anthesis until late morning. As suggested by Cody (1971) for birds, independent bee foraging may be favored at an abundant resource, such as the $C$. arvensis patch. However, the bees' foraging patterns may vary in response to different resource patterns or different bee densities.

Further investigations, using similar and different censusing techniques, are needed to elucidate bee foraging patterns in relation to resource patterns. Studies of several bee species may suggest some general patterns.

\section{ACKNOWLEDGMENTS}

I thank M. D. Breed, C. D. Michener, T. P. Snyder, and B. L. Waddington for helpful suggestions on the manuscript. Thanks also to R. W. Thorpe, University of California, Davis, for permitting me to see unpublished data. 


\section{Literature Cited}

Bernstein, R. A.

1975. Foraging strategies of ants in response to variable food density. Ecology, 56: 213-219.

CoDy, M. L.

1971. Finch flocks in the Mohave Desert. Theor. Pop. Biol., 2: 142-158.

Frankie, G. W., P. A. Opler and K. S. Bawa.

1974. Foraging behavior of solitary bees: Implications for outcrossing of a neotropical forest tree species. (Unpub. m.s.).

Heithaus, E. R., P. A. Opler and H. G. Baker.

1974. Bat activity and pollination of Bauhinia pauletia: Plant-pollinator coevolution. Ecology, 55: 412-419.

Kalmus, $\mathbf{H}$.

1953. The clustering of honeybees at a food source. Brit. J. Anim. Behav., 2: 63-71.

Pielou, E. C.

1969. An Introduction to Mathematical Ecology. New York: Wiley-Interscience. 286 pp.

RICKLEFS, R. E.

1973. Ecology. Newton, Massachusetts: Chiron Press. 861 pp.

Rohlf, F. J. and R. R. Sokal

1969. Statistical Tables. San Francisco: W. H. Freeman and Company, 253 pp.

SOKAL, R. R. AND F. J. ROHLF

1969. Biometry. San Francisco: W. H. Freeman and Company. 776 pp. WARD, P.

1965. Feeding ecology of the black-faced dioch Quelea quelea in Nigeria. Ibis, 107: 173-214. 

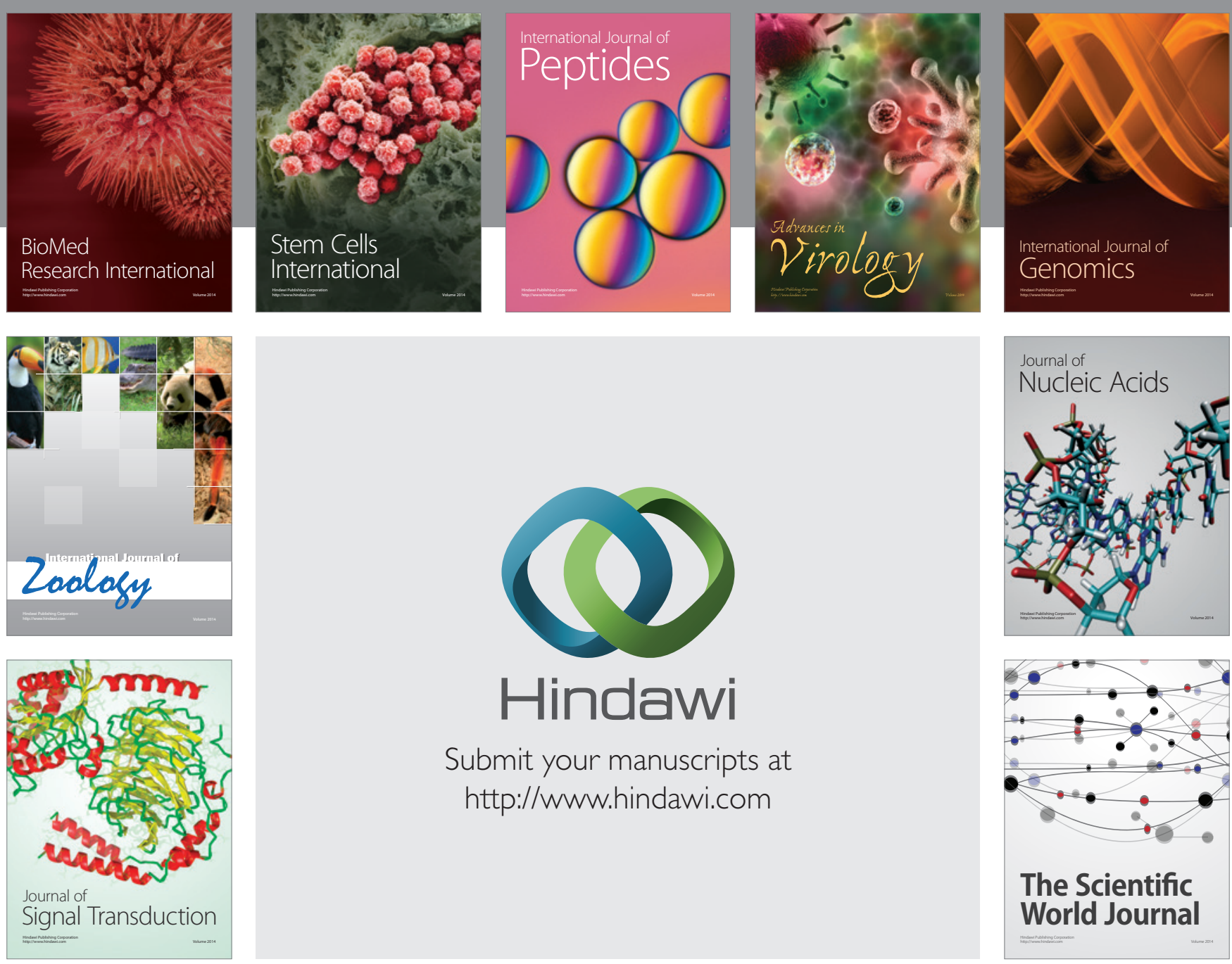

Submit your manuscripts at

http://www.hindawi.com
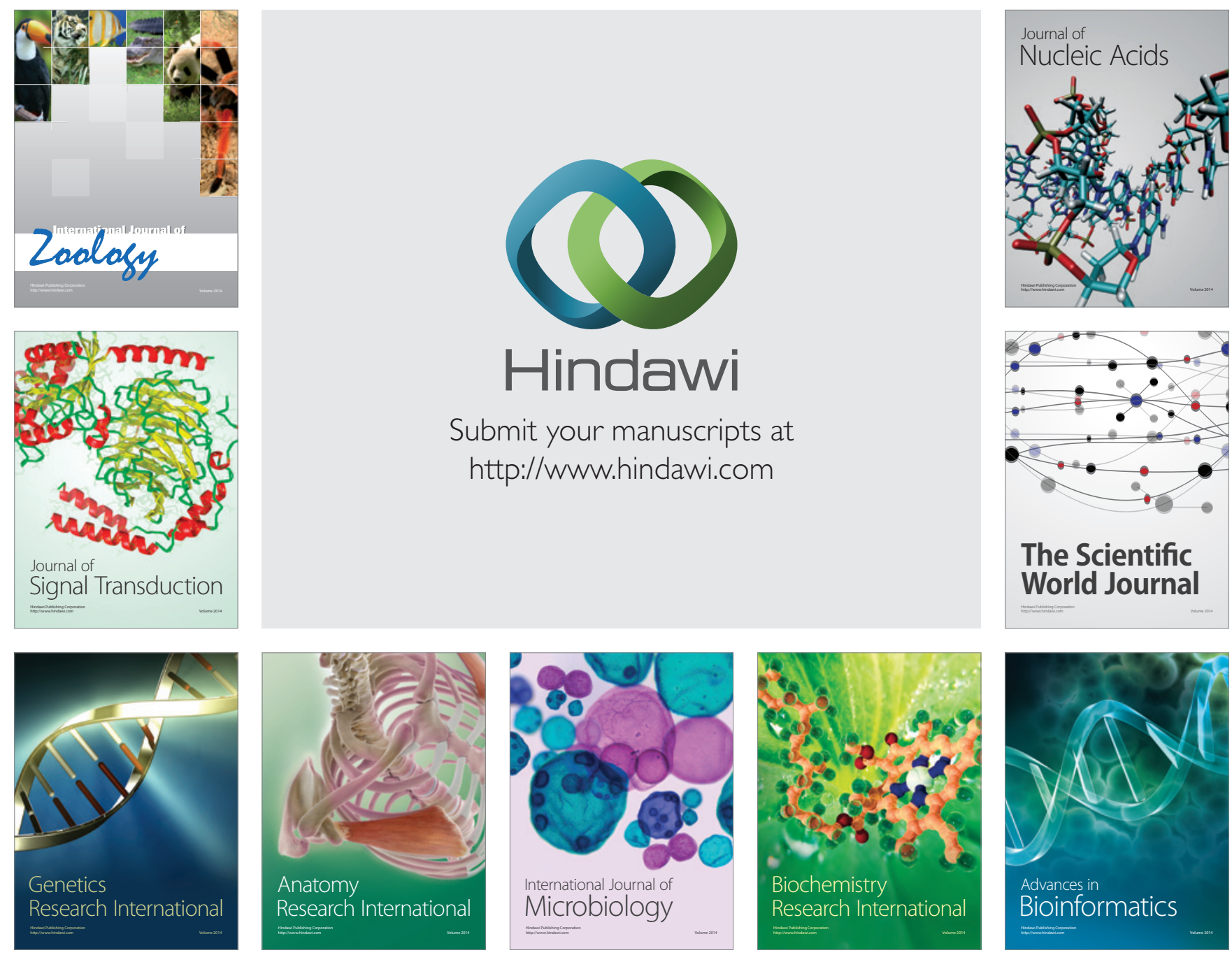

The Scientific World Journal
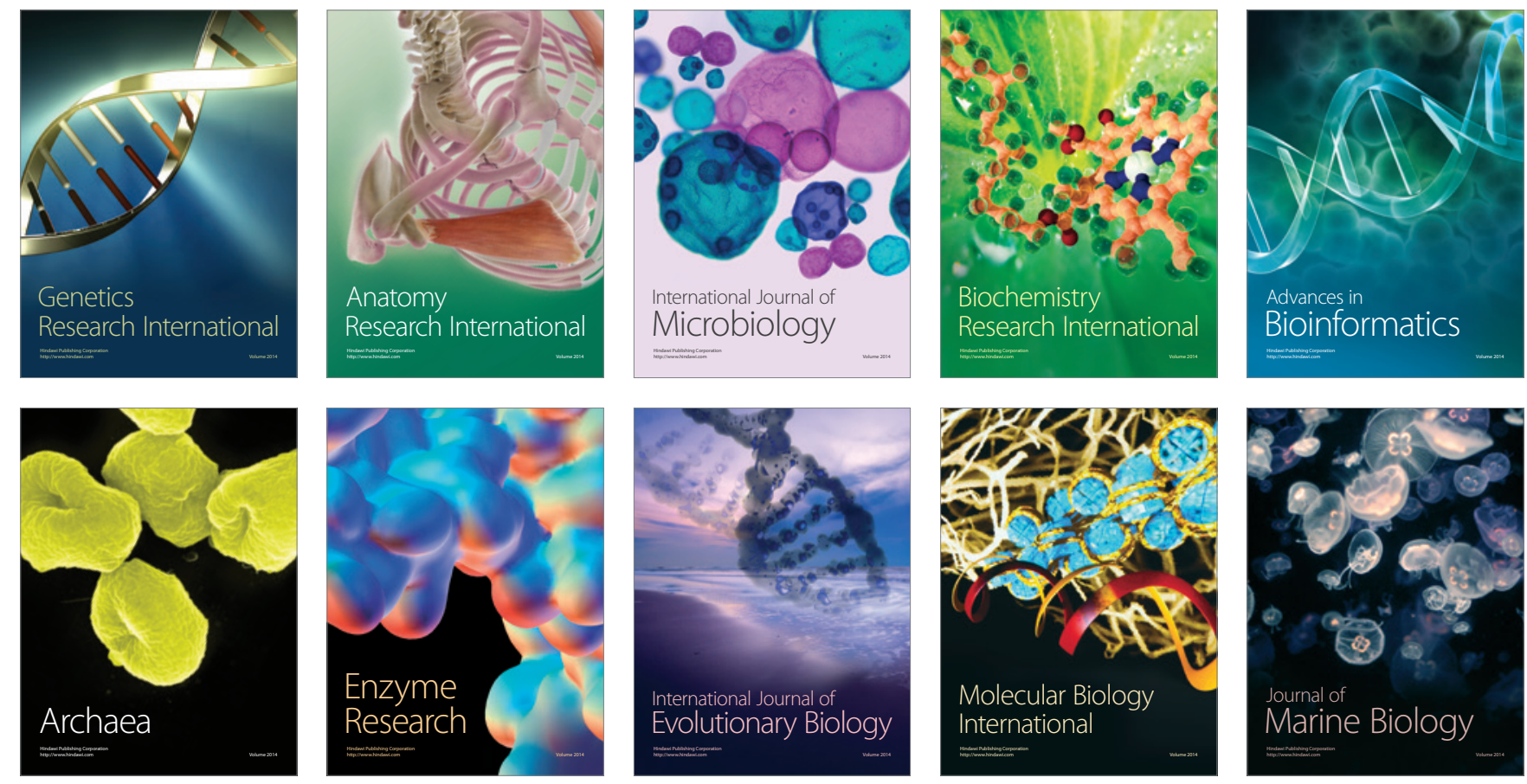